\title{
Norwegian Nurse Managers' Perceptions of Ethical Conflicts in Community Healthcare When Caring for Older Persons Who Wish to Die
}

\author{
Anne Lise Holm¹, Astrid Karin Berland1, Elisabeth Severinsson ${ }^{2}$ \\ ${ }^{1}$ Department of Health Science, Western Norway University of Applied Sciences, Haugesund, Norway \\ ${ }^{2}$ Centre for Women's, Family and Child Health, Faculty of Health and Social Science, University College of Southeast Norway, \\ Kongsberg, Norway \\ Email: anne.holm@hvl.no, astrid.berland@hvl.no,elisabeth.severinsson@usn.no
}

How to cite this paper: Holm, A.L., Berland, A.K. and Severinsson, E. (2017) Norwegian Nurse Managers' Perceptions of Ethical Conflicts in Community Healthcare When Caring for Older Persons Who Wish to Die. Open Journal of Nursing, 7, 1274-1288.

https://doi.org/10.4236/ojn.2017.711092

Received: October 9, 2017

Accepted: November 17, 2017

Published: November 21, 2017

Copyright () 2017 by authors and Scientific Research Publishing Inc. This work is licensed under the Creative Commons Attribution International License (CC BY 4.0).

http://creativecommons.org/licenses/by/4.0/

\begin{abstract}
The complexity of the healthcare organization with emphasis on efficiency and productivity has led to an increase in value conflicts as well as moral and ethical conflicts. The aim of this study was to explore nurse managers' perceptions of ethical conflicts when caring for older patients who wish to die. A qualitative method was employed and data were collected by means of a focus group interview with eight nurse managers. The results revealed one theme: $A$ struggle due to responsibility for decision making and four sub-themes: Understanding the meaning of free will, wondering about how serious the death wish is, providing more worthy elder care and lack of competent healthcare professionals to provide safe care. Nurse managers' have no structure for bringing ethical conflicts to the attention of their leaders or the next level of the organization. Consequently, they appear to need supervision, support and clear, flexible lines of communication with leadership.
\end{abstract}

\section{Keywords}

Death Wishes, Ethical Conflicts, Focus Group, Home Healthcare,

Older Patients

\section{Introduction}

Nurse managers play an important role in the working environment in home health care [1]. They have great responsibility for determining and planning their subordinates' work [2] [3] [4]. According to Anthony et al. [5], nurse managers have the most demanding work schedules in the community healthcare services. Changes in the role have affected their subordinates' work, as it has 
become increasingly difficult to provide the previous level of support [1] [6]. Nurse managers are expected to act as representatives of their organization and an ethical conflicts occurs when they are told to do something that is contrary to their ethical values and principles [7]. Ethical conflicts can also arise when nursing and organizational values differ and where competition is highlighted [8]. The complexity of the healthcare organization with emphasis on efficiency and productivity has led to an increase in value conflicts as well as moral and ethical challenges [8].

Nurse managers are responsible for the community healthcare of older patients who are tired of living and wish to die. Such death wish can be complex and is not always articulated. Sometimes such wishes can be seen as death ideation related to suicide or physician-assisted suicide. Optimal home healthcare cannot always prevent many older patients from becoming tired of living and developing the wish to die, which is sometimes due to the fact that aging leads to a reduced sense of meaning in life. Previous studies have revealed this phenomenon in 5\% - 25\% of older persons [9] [10] [11] [12]. Death wishes can be related to physical and mental health problems and sometimes to loneliness, a small social network, lack of control and living in residential care [9] [13] [14]. However, it has been shown that despite having a death wish older people do not necessarily want to fulfill it. In home healthcare, deciding what to do for patients who are tired of living and want to die can be an impossible task, leading to ethical conflicts for nurse managers as well as for home healthcare professionals as it is impossible to know whether the older patient will actively attempt to fulfil her/his death wish. Scocco and De Leo [11] make a distinction between passive and active death ideation. Passive death ideation means that a person wants to die but does not pursue this wish, while active death ideation implies that a person seriously considers taking her/his own life. The estimated prevalence of active death ideation among older persons is $1 \%$ - 9\% [11] [12]. In contrast to the Netherlands, physicians in Norway have no legal right to participate in assisted suicide and no care criteria exist [15]. The decision to stop eating and drinking is legal throughout the United States for competent patients and does not necessarily require the participation of a physician [16] [17]. Pasman et al. [18] explored the views of patients and physicians in the context of suffering patients who requested euthanasia and whose request was either not granted or granted but not performed. The results showed that not all patients who requested euthanasia considered their suffering unbearable, although they had a strong wish to die [18].

The debate on how to determine the time and manner of death has become more common, as these aspects are considered important indicators of a "good death" in western countries [19]. Many factors need to be considered and the complexity of this concept must be recognized. In addition to a growing awareness of death and dying, values such as self-determination, autonomy and individualism have become more dominant [19]. Lloyd [20] has described how the 
emphasis on autonomy and independence in Western cultures can result in older people becoming marginalised because of their dependency and vulnerability. There is a risk that the needs of older people will not be met [21] Franklin et al. [22] found that the attitudes of those around older people could both promote and hinder their dignity of identity. Several years ago MacKenzie [23] stated that ethical conflict can be related to an individual's consciousness, which can be difficult to understand because several views are present in her/him at the same time [23]. An ethical conflict can be seen as an inner struggle within the individual. Ethical conflicts in home healthcare can be considered part of an effort to increase the quality of important professional initiatives by exploring what home health care managers and workers consider difficult ethical conflicts and challenges [24]. They are often related to the needs of the patient and the ethical standards of the profession on the one hand, and economic and organizational conditions on the other [24].

It can be difficult to gain a sufficient overview of the needs of older patients who have expressed that they are tired of living.

\section{Aim}

The aim of this study was to explore nurse managers' perceptions of ethical conflicts when caring for older patients who wish to die.

\section{Methods}

\subsection{Sample}

A focus group interview was used to explore nurse managers' reflections on home healthcare. Focus group interviews are described as an appropriate method for investigating experiences, reflections, perceptions, opinions, wishes and concerns [25], thus best suited for an analysis and discussion of complex themes [26]. This method captures the relationships between participants and is a way to understand how individuals feel and think about a specific issue. The participants' experiences and perceptions can facilitate a valuable discussion where different views are obtained [27].

The sample consisted of eight female nurse managers $(n=8)$ in order to obtain different perceptions [28]. The nurse managers were employed in home healthcare in three communities in a county on the West coast of Norway. Additional demographic characteristics are presented in Table 1.

In the recruitment process, leaders of 12 different communities were informed of the project in the course of a meeting at a University College. The topic of the meeting was the challenge of older patients who wish to die. The 12 communities were contacted by e-mail and four expressed interest in participating in the project. However, when an invitation to participate was sent in February 2016, three of these communities declined. The first author (ALH) then phoned several of the communities that were initially invited to participate, leading to the formation of a focus group with eight participants from three communities. This 
Table 1. Demographic characteristics of the participants.

\begin{tabular}{|c|c|c|c|c|}
\hline $\begin{array}{l}\text { Community } \\
\qquad(\mathrm{n}=3)\end{array}$ & $\begin{array}{c}\text { Age } \\
(\mathrm{n}=8)\end{array}$ & Sex & $\begin{array}{l}\text { Time as } \\
\text { nurse } \\
\text { manager }\end{array}$ & Education \\
\hline A & 41 & Female & 2 years & $\begin{array}{l}\text { Gastro nursing, } \\
\text { palliative care. }\end{array}$ \\
\hline A & 46 & Female & 4 years & $\begin{array}{l}\text { Mental health nursing, } \\
\text { social pedagogics. }\end{array}$ \\
\hline A & 26 & Female & Six months & Registered nurse. \\
\hline B & 46 & Female & Six months & $\begin{array}{c}\text { Geriatric nursing, administrative } \\
\text { education. }\end{array}$ \\
\hline B & 51 & Female & Six months & $\begin{array}{l}\text { Cancer nursing, administrative } \\
\text { education. }\end{array}$ \\
\hline $\mathrm{C}$ & 55 & Female & 2 years & $\begin{array}{c}\text { Geriatric nursing, administrative } \\
\text { education. }\end{array}$ \\
\hline $\mathrm{C}$ & 60 & Female & Over 10 years & Registered nurse. \\
\hline $\mathrm{C}$ & 54 & Female & Over 10 years & $\begin{array}{l}\text { Mental health and geriatric nursing, } \\
\text { administrative education. }\end{array}$ \\
\hline
\end{tabular}

sample size has been described as suitable in a focus group interview [28].

\subsection{Data Collection}

Data collection was performed by means of one focus group interview that lasted between 1.5 and 2 hours in May 2016 at the University. The first author (ALH) acted as moderator and led the discussion, posing introductory and open-ended questions. The main question to the focus group was; What do you experience as most problematic in your role as a nurse managers when caring for older patients who wish to die? The focus group interview was digitally recorded and transcribed verbatim by the first author.

\subsection{Data Analysis}

The qualitative analysis of the transcripts was conducted by the first author (ALH). The data were analysed according to three levels of interpretation described by Kvale and Brinkmann [29]. The first level, i.e., self-understanding, consisted of the meaning of the participants' statements. The interpretation can be described as a circular process that moved back and forth between the parts and the whole of the text, a process that Gadamer [30] called the hermeneutical circle. In the second level, i.e., critical understanding, the researchers used common sense and a critical approach to the interpretation, posing questions such as: What is the content of the participants' statements? Focus group interviews have been described as enabling a search for common patterns as well as differences in the transcribed text [29]. This interpretation can be perceived as a frame of reference for obtaining a deeper understanding of the participants based on the researchers' own pre-understanding as mental health nurses (ALH, 
ES) and an anaesthesia nurse (AB). The third level, i.e., theoretical understanding, involves the construction of a theoretical framework, which in this case were mainly ethical [23]. The meaning of the text was structured in the form of a table to identify the themes and sub-themes. Throughout the whole process the results were validated by discussing how they could be understood and interpreted (Table 2).

\subsection{The Truthfulness of the Analysis}

The researchers are responsible for ensuring the trustworthiness of the research process and the truthfulness of the analysis. Kvale and Brinkmann [29] argue that validity and reliability are something we use in everyday language. Trustworthiness does not always seem to have a methodological meaning, but according to Kvale and Brinkmann [29], a moral person is trustworthy. Reliability concerns the consistency and trustworthiness of the results and is based on a range of criteria for assessing the "truth value", including a systematic collection of data throughout the research period [31]. Validity refers to assessing the truth value in a way that inspires confidence in the data, in addition to reflecting multiple realities [32]. For these reasons, a focus group interview as a qualitative research method seems to imply a broader interpretation of validity than is the case in quantitative research. An important criterion for judging the methodological quality is whether or not the researchers explored what they set out to explore.

\subsection{Limitation}

The small number of participants in this focus group makes it difficult to claim transferability to other home health care settings in Norway or other countries. More research is required to explore the ethical conflicts experienced by nurse managers working in home health care in in different parts of the world.

\subsection{Ethical Considerations}

The participants were informed about the purpose, method and their right to withdraw from the study at any time. They were assured that the data would be treated confidentially and that their names would be removed from the transcripts [33]. The study was approved by the Norwegian Social Science Data Services (No. 44782) and carried out in accordance with the Ethical guidelines for nursing research in the Nordic countries [34].

Table 2. The results of the qualitative thematic data analysis.

Theme
A Struggle Due to Responsibility for Decision Making
Understanding the Meaning of Free Will
Wondering About How Serious the Death Wish is
Providing More Worthy Elder Care




\section{Results}

The results revealed one theme; $A$ struggle due to responsibility for decision making and four sub-themes; Understanding the meaning of free will, Wondering about how serious the death wish is, Providing more worthy elder care and Lack of competent healthcare professionals to provide safe care.

\subsection{A Struggle Due to Responsibility for Decision Making}

The theme revealed that nurse managers experience distress, which leads to exhaustion, because they are unsure of own responsibility when faced with ethical conflict at work. They have few or no effective strategies to provide safe care for older patients who wish to die. The nurse managers have few strategies for managing this inner struggle especially bringing them to the attention of their leaders. Instead, they try to handle the distress related to the ethical dilemmas themselves. Often they try to support their staff such as nurses and general practitioners (GPs). On several occasions they referred to their responsibility as ethical conflicts or dilemma as; "this is experienced as an ethical dilemma for us".

\subsubsection{Understand the Meaning of Free Will}

The participants revealed that they feel responsible when they hear desire to die statements from older patients. They try to understand the meaning of free will and one participant asked herself if the older patients have a free will including a right to decide when and where to die? Some of the participants stated that elderly people who live alone and feel lonely have nothing to live for. Another participant agreed and commented that such statements raised ethical conflict. She posed the following question;

"What strategies can be employed to handle the situation when an older patient expresses that shel he has lived long enough and wants to be relieved of her/his suffering?"

Such questions were interpreted as a wish to die at home and called "planned home-death". The same participant stated that;

"When I experience older persons refusing to eat and becoming thinner and thinner every week I really do not know what to do".

Some of the participants revealed that they often had to make decisions based on their view of the patient's need for autonomy. Such decision-making must take account of free will and acknowledge that the patient has a right to decide when and where to die. Another participant added that in such a situation it must be established that a patient has no cognitive defect or mental illness. The moderator $(\mathrm{ALH})$ asked if this decision can be considered to involve a form of euthanasia or physician assisted suicide and the participants confirmed that as the correct interpretation.

\subsubsection{Wondering about How Serious the Death Wish Is}

Some of the participants explained that they tried to make a decision based on the risk of suicide. The discussion revealed that suicide in the elderly and the 
wish to die does not seem to be on the agenda in the homecare services. In general, healthcare professionals are not sure about how to deal with this issue and are often uncertain about what questions to ask if elderly patients express that they do not want to live. This was seen as a barrier to developing a dialogue about older patients' intentions, as demonstrated by the following quotation;

"An ethical dilemma arises when the healthcare professional has to stay for a longer time because she/ he is unsure about what to do and the time flies by. You have to make a decision about whether the older patient has a plan and how serious it is. This is horrible, as you have other patients on the list".

The discussion revealed that ethical conflicts arise when elderly patients express that they want to take their own life with an overdose of their tablets or insulin because they are feeling unsafe.

\subsubsection{Providing More Worthy Elder Care}

The focus group discussion revealed the conflict pertaining to the question of why so many are tired of living and do not wish to live and whether it might be related to feeling worthless in society. The elderly seem to be in a vulnerable situation, with a sense of being superfluous and a burden. The participants added that many health care professionals of other nationalities working in the home health care are shocked about how we take care of the elderly. In their cultures elderly individuals are treated in a more dignified manner. One participant asked whether elderly persons in our culture experience a lack of worth and feel that they are treated in an undignified manner and if so, why? One of the patients stated this;

"You experience having nothing more to offer. The patients have no hope for the future. The things they could do before are gone and their statements can be interpreted to mean that they feel increasingly worthless".

\subsubsection{Lack of Competent Healthcare Professionals to Provide Safe Care}

The focus group discussion revealed that an ethical conflict arises when there is a lack of professional competence that could give the patient a choice living a dignified life at home. Although the notion that everyone should be permitted to live at home until their last day is wonderful, there seems to be a lack of coordination between several services. The participants reported experiencing a turbulent period in two of the included communities. One stated;

"These elderly patients often want healthcare professionals close at hand who they can trust. They become afraid and are terrified of being left alone".

\section{Discussion}

The theme, $A$ struggle due to responsibility for decision making, concerned the fact that the participants seem to experience ethical conflicts in decision making on a daily basis in home healthcare in Norwegian communities. Ethical conflicts can be seen as dilemmas and have been described as uncertainty about making the right decision in different situations and justifying such decisions [35]. Ethi- 
cal conflicts can be related to conflicting inner values, norms and interests knowing the right thing to do, but institutional or other constraints making it difficult to pursue the desired action [36] [37]. Thus, nurse managers' can be stressed by their awareness of competing or contradictory ethical imperatives. [38] According to MacKenzie, [23] an individual may be influenced by considerations drawn from reflections based on personal ambition, the welfare of her/his family, duty to the world, or religious beliefs. Such views may arise in one's mind and some can conflict with others, after which it becomes a question of which of these views the individual finally chooses [23]. Different factors can contribute to uncertainty pertaining to ethical conflicts in decision making, causing feelings of frustration about which actions are consistent with one's conscience [39]. One important issue for nurse managers is to do what is right and good in their work [40]. However, studies have revealed that nurse managers generally feel uncertain about how to manage their subordinates with regard to ethical conflicts and dilemmas [41].

Responsibility can be seen as a relational way of being that involves being guided by one's inner ideals, values and knowledge, in addition to struggling to do good. Ethical conflicts seem to arise when one experiences being unable to act in a good enough way. Nurse managers' ethical conflicts appear to be related to a sense of failure to assume responsibility [42]. They seem to struggle with responsibility because they are not quite sure how to act. Redman [43] stated that a professional's responsibility for achieving patient goals must be based on the notion that human beings are moral agents with their own values.

The demand for ethical conflicts in decision making in community healthcare is increasing [44]. However, nurse managers seem to lack commitment to ethics and have few ethical support groups to ensure trusting relationships [44]. Lack of reflection on and discussions of ethical problems and/or conflicts can lead to moral distress [45]. Thus, nurse managers can become distressed by their reactions, as well as by their awareness of competing or contradictory ethical imperatives

Understanding the meaning of free will can be related to autonomy, which involves independence, self-determination and self-care. It is a balancing act, as an ethical problem can arise because of the vulnerability of the elderly patients, often related to their experience of emotional pain and suffering. Ethical conflict can also occur when nurse managers have used force or pressure in response to a situation. Autonomy is central to the notion of independence [46]. The word "autonomy" comes from the Greek words "autos" meaning "self" and "nomos" meaning "rule", which can be translated into the term "self-rule" [47]. The concept can thus be seen as exercising individual choice, freedom, free will and assuming responsibility for one's own behaviour and/or self [46]. Autonomy can refer to what makes a life one's own based on personal preferences and choices [48]. Beauchamp and Childress [48] have outlined four points that characterise a person's autonomy; Being free from the controlling influence of others; Being 
free from limitations that prevent meaningful choice; Being free from inadequate understanding and Being able to freely act in accordance with a self-chosen plan. Based on these four points, liberty and agency appear to be two conditions for autonomy [46]. Negative and stereotypic bias results in elderly people experiencing how society views old age. These biased attitudes can reinforce discriminatory practices, such as dependency and infantilisation of the elderly [46] and what Butler [49] called ageism. Ageing is thus seen as a social problem and not a natural process. A consequence of ageism is that elderly people experience social death as a result of paternalistic and infantilising practices, in addition to loss of the right to autonomous behaviour. Ageism can be seen through the attitudes and actions of homecare nurse and healthcare professionals, causing them to overlook older patients' symptoms or misinterpret them as illness instead of a natural process of aging. Wondering about how serious the death wish is seems to be related to whether or not the older patient is suicidal. If the patient trusts the healthcare professional, she/he will tell about the plan to take an overdose of tablets or similar. The homecare professional is responsible for immediately contacting the GP or nurse manager, as such messages can be serious. Sometimes it can be sufficient to devote more time to the elderly patient and encourage her/him to talk about the emotional pain and suffering. However, research has revealed negative attitudes towards suicide among nurses [50]. The belief that a person does not have the right to commit suicide was stronger among older nurses, those who had never taken care of suicidal patients, had a family history of suicide, who were Protestants and attended church services more frequently. Greater professional capacity was reported by nursing assistants and nurses who had already taken care of suicidal patients [50]. Such negative attitudes can be sensed by the older patients, causing them to conceal their serious suicidal plans.

The ethical conflict experienced by nurse managers in meeting older patients' need to be seen as unique seems to be associated with showing respect and viewing the individual as a human being and not just a patient. Such attitudes can be a question of professional ethical knowledge where the value of a human being is related to uniqueness and respect. Another concept in this field is expert knowledge, which can be a way to change attitudes about older individuals. Awareness of the implications of ageism can help one to understand how to strengthen an older individual's self-determination [49]. Healthcare has been described as a moral endeavour, thus failure to do "good" can result in a troubled conscience, aggravated by the fact that professionals demand high standards from themselves in their contact with patients [51]. Feeling that one is personally responsible for the quality of care and being uncertain about one's professional responsibility have been reported as potential stress factors [52] [53] [54]. Ethical conflicts can arise due to lack of awareness of and attention to the moral aspects, making people less attentive to their conscience. Individuals who are aware of their inner ethical conflicts can be more attentive can focus 
more on their own role and responsibility [54] [55]. In the context of elder care, autonomy can be defined as the extent to which healthcare professionals explore older patients' perspectives, support their initiatives, offer a choice of caring options and provide relevant information while minimizing pressure and control [56].

Providing more worthy elder care can be related to our finding that in other countries families take care of their elderly relatives, which could be based on cultural expectations. In Norway, families expect the community to take over the care of their elderly family member. Hearing such statements must be difficult for the older persons. Research has revealed that older persons feel they have become a burden to their families [57], which could be due to negative attitudes to the elderly in our society. In the aforementioned study, the older persons described feeling unworthy. Worthiness can be related to dignity of identity. A sense of dignity is described as the most important sense in the context of dignity and illness as well as in the context of dignity and ageing [58]. Dignity can be taken away by the acts of other people, by injury, illness and old age. It is something that we attach to ourselves as integrated and autonomous persons with a history, a future and relationships to other human beings [58]. As Nordenfelt ([58] p. 75) stated "this must be a dignity attached to the person's integrity and identity as a human being". As the participants in this study revealed, older patients who wish to die are often referred to as being "tired of living" [59].

In a study by McDonough and Polzer [60], in-depth interviews with 45 front line workers revealed frustration with their working conditions and relationships with management. These inner conflicts were described as a "symbolic context of restructuring: the struggle to redefine governance and public services provision in the name of greater efficiency, effectiveness and accountability" ([60] p. 372).

Feeling safe can be seen as a basic goal in home care nursing, which is related to existential theories outlined by Eriksson [61] as fundamental in nursing care. A sense of unsafety can be associated with feeling excluded and worthless, but might also involve a real fear related to the increased risk of falls. Another aspect may be media focus on violence against elderly people. In such situations a suicide plan can emerge where older patients actually do something active about their death wishes, such as jumping from the stairs of their second floor apartment. While this may be more in the nature of a cry for help, it can also be seen as a serious illustration of their distress, fear, pain and suffering.

\section{Recommendation}

Research findings recommend that nurse managers need knowledge and skills to manage their subordinates in the decision-making process [56]. Several leadership styles exist [62] and nurse managers have to make decisions based on ethical problems and/or conflicts [36] [40]. Organization, culture, power relations, quality of care and experiences of safety must also be taken into account [62] 
[63]. Nurse managers need to clarify their own values and enhance understanding among nurses, patients and other healthcare professionals based on shared decision-making [40] [64] [65].

\section{Conclusion}

Nurse managers' have no structure for bringing ethical conflicts to the attention of their leaders or the next level of the organization. Consequently, they appear to need supervision, support and clear, flexible lines of communication with leadership. Support can help to prevent feelings of helplessness and powerlessness in situations where they experience ethical conflicts. However, it may be difficult to find one correct leadership style in the decision-making process. Such processes should be based on contextual factors where nurse managers can shape an environment together with staff that allows sufficient time to reflect on ethical conflicts in different community home healthcare contexts and situations.

\section{Acknowledgements}

The authors thank nurse managers for their valuable contribution to the study. We also thank Monique Federsel for reviewing the English.

\section{References}

[1] Shirey, M.R. (2009) Stress and Coping in Nurse Managers: A Qualitative Description. School of Nursing, Indiana University, Bloomington.

[2] Nilsson, K. (2003) Mandate - Power - Management: A Study of how Care Managers Leadership Is Constructed. Dissertation (En Studie av Hur Vårdenhetschefers Ledarskap Konstrueras) Dissertation, Acta Universitatis Gothoburgensis, Göteborg. (In Swedish)

[3] Thorpe, K. and Loo, R. (2003) Balancing Professional and Personal Satisfaction of Nurse Managers: Current and Future Perspectives in a Changing Health Care System. Journal of Nursing Management, 11, 321-330. https://doi.org/10.1046/j.1365-2834.2003.00397.x

[4] Patrick, A. and Laschinger, H.K. (2006) The Effect of Structural Empowerment and Perceived Organizational Support on Middle Level Nurse Managers' Role Satisfaction. Journal of Nursing Management, 14, 13-22. https://doi.org/10.1111/j.1365-2934.2005.00600.x

[5] Anthony, M.K., Standing, T.S., Glick, J., Duffy, M., Paschall, F., Sauer, M.R., Kosty, D., Modic, M.B. and Dumpe, M. (2005) Leadership and Nurse Retention: The Pivotal Role of Nurse Managers. Journal of Nursing Administration, 35, 146-155. https://scholar.google.no/scholar?hl=no\&as_sdt=0\%2C5\&q=Anthony\%2C+M.K.\%2 $\mathrm{C}+$ Standing $\% 2 \mathrm{C}+$ T.S. $\% 2 \mathrm{C}+\mathrm{Glick} \% 2 \mathrm{C}+\mathrm{J} . \% 2 \mathrm{C}+\mathrm{Duffy} \% 2 \mathrm{C}+\mathrm{M} . \% 2 \mathrm{C}+\mathrm{Paschall} \% 2 \mathrm{C}+\mathrm{F}$ $\% 2 \mathrm{C}+$ Sauer\%2C+M.R.\%2C+Kosty\%2C+D.\%2C+Modic\%2C+M.B.\%2C+and+Du mpe $\% 2 \mathrm{C}+$ M.+\%282005\%29+Leadership + and + Nurse+Retention $\% 3 \mathrm{~A}+$ The+Pivotal + Role+of+Nurse+Managers\&btnG https://doi.org/10.1097/00005110-200503000-00008

[6] Doran, D., Sanchez McCutcheon, A., Evans, M.G., MacMillan, K., McGillis Hall, L., Pringle, D., Smith, S. and Valente, A. (2004) Impact of the Manager's Span of Con- 
trol on Leadership and Performance. Canadian Health and Long-Term Care Nursing Effectiveness, Utilization and Outcomes Research Unit, Faculty of Nursing, University of Toronto, Ontario.

https://scholar.google.no/scholar?hl=no\&as_sdt=0\%2C5\&q=Doran $\% 2 \mathrm{C}+\mathrm{D} . \% 2 \mathrm{C}+\mathrm{S}$ an-

chez+McCutcheon $\% 2 \mathrm{C}+\mathrm{A} . \% 2 \mathrm{C}+$ Evans $\% 2 \mathrm{C}+\mathrm{M} . \mathrm{G} . \% 2 \mathrm{C}+\mathrm{MacMillan} \% 2 \mathrm{C}+\mathrm{K} . \% 2 \mathrm{C}+$ McGil-

lis+Hall $\% 2 \mathrm{C}+\mathrm{L} . \% 2 \mathrm{C}+$ Pringle $\% 2 \mathrm{C}+\mathrm{D} . \% 2 \mathrm{C}+$ Smith $\% 2 \mathrm{C}+\mathrm{S} .+$ and + Valente $\% 2 \mathrm{C}+\mathrm{A} .+$ $\% 282004 \% 29+$ Impact+of +the+Manager\%E2\%80\%99s+Span+of+Control+on+Lead ership+and+Performance\&btnG

[7] Gaudine, A.P. and Beaton, M.R. (2002) Employed to Go against One's Values: Nurse Managers' Accounts of Ethical Conflict with their Organizations. Canadian Journal of Nursing Research, 34, 17-34.

[8] Skytt, B., Ljungren, B. and Carlsson, M. (2008) The Roles of The First-Line Nurse Manager: Perceptions From Four Perspectives. Journal of Nursing Management, 16, 1012-1020. https://doi.org/10.1111/j.1365-2934.2006.00684.x

[9] Rurup, M.L., Pasman, H.R.W., Goedhart, J., Deeg, D.J.H., Kerkhof, A.J.F.M. and Onwuteaka-Philipsen, B.D. (2011) Understanding Why Older People Develop a Wish to Die: A Qualitative Interview Study. Crisis, 32, 204-216. https://doi.org/10.1027/0227-5910/a000078

[10] Barnow, S. and Linden, M. (2000) Epidemiology and Psychiatric Morbidity of Suicidal Ideation among the Elderly. Crisis, 21, 171-180. https://doi.org/10.1027//0227-5910.21.4.171

[11] Scocco, P. and De Leo, D. (2002) One-Year Prevalence of Death Thoughts, Suicide Ideation and Behaviours in an Elderly Population. Internal Journal of Geriatric Psychiatry, 17, 842-846. https://doi.org/10.1002/gps.691

[12] Scocco, P., Fantoni, G., Rapattoni, M., de Girolamo, G. and Pavan, L. (2009) Death Ideas, Suicidal Thoughts, and Plans among Nursing Home Residents. Journal of Geriatric Psychiatry \& Neurology, 22, 141-148. https://doi.org/10.1177/0891988709332937

[13] Rurup, M.L., Deeg, D.J.H., Poppellaars, J.L., Kerkhof, A.J.F.M. and Onwuteaka-Philipsen, B.D. (2011) Wishes to Die in Older People: A Quantitative Study of Prevalence and Associated Factors. Crisis, 32, 194-203. https://doi.org/10.1027/0227-5910/a000079

[14] Dennis, M.S., Wakefield, P., Molloy, C., Andrews, H. and Friedman, T. (2007) A study of Self-Harm in Older People: Mental Disorder, Social Factors and Motives. Aging \& Mental Health, 11, 520-525. https://doi.org/10.1080/13607860601086611

[15] Raijmakers, N.J.H., Van der Heide, A., Kouwenhoved, P.S.C., Van Thiel, G.J.M.W., Van Delden, J.J.M. and Rietjens, J.A.C. (2015) Assistance in Dying for Older People without a Serious Medical Condition Who Have a Wish to Die: A National Cross-Sectional Survey. Journal of Medical Ethics, 41, 145-150. https://doi.org/10.1136/medethics-2012-101304

[16] Quill, T.E. and Byock, I.R. (2000) Responding to Intractable Terminal Suffering: The Role of Terminal Sedation and Voluntary Refusal of Food and Fluids. Annals of Internal Medicine, 132, 408-414. https://doi.org/10.7326/0003-4819-132-5-200003070-00012

[17] Ganzini, L., Goy, E.R., Miller, L.L., Harvath, T.A., Jackson, A. and Delorit, M.A. (2003) Nurses' Experiences with Hospice Patients Who Refuse Food and Fluids to Hasten Death. The New England Journal of Medicine, 349, 359-365. 
https://doi.org/10.1056/NEJMsa035086

[18] Pasman, H.R., Rurup, M.L., Willems, D.L. and Onwuteaka-Philipsen, B.D. (2009) Concept of Unbearable Suffering in Context of Ungranted Requests for Euthanasia: Qualitative Interviews with Patients and Physicians. BMJ, 16, b4362. https://doi.org/10.1136/bmj.b4362

[19] Cabot, B.E. and Goedhart, A. (2009) A Survey of Self-Directed Dying Attended by Proxies in the Dutch Population. Social Science \& Medicine, 68, 1745-1751. https://doi.org/10.1016/j.socscimed.2009.03.005

[20] Lloyd, L. (2004) Mortality and Morality; Ageing and the Ethics of Care. Ageing Society, 24, 235-256. https://doi.org/10.1017/S0144686X03001648

[21] Ternestedt, B.-M. and Franklin, L.-L. (2006) Ways of Relating to Death: Views of Older People Resident in Nursing Homes. Internal Journal of Palliative Nursing, 12, 334-340. https://doi.org/10.12968/ijpn.2006.12.7.21611

[22] Franklin, L., Ternestedt, B.-M. and Nordenfelt, L. (2006) The View on Dignity of Twelve Elderly Nursing Home Residents. Nursing Ethics, 13, 130-146. https://doi.org/10.1191/0969733006ne851oa

[23] Mackenzie, J.S. (1946) A Manual of Ethics. University Tutorial Press Ltd, Clifton House, London.

[24] Gjerberg, E., Førde, R., Pedersen, R. and Bollig, G. (2010) Ethical Challenges in the Provision of End-of-Life Care in Norwegian Nursing Homes. Social Science of Medicine, 71, 677-684. https://doi.org/10.1016/j.socscimed.2010.03.059

[25] Barbor, R.S. and Kitzinger, J. (1999) Developing Focus Group Research. Sage Publications, London.

[26] Kvarme, L.G., Helseth, S. and Natvig, G.K. (2009) School Children's Experience of Being Bullied-and How They Envisage Their Dream Day. Scandinavian Journal of Caring Science, 24, 791-798. https://doi.org/10.1111/j.1471-6712.2010.00777.x

[27] Wilkinson, D. (2004) Focus Group Research. Qualitative Research Theory, Method and Practice. SAGE Publications, London.

[28] Polit, D.F. and Beck, C.T. (2012) Nursing Research: Generating and Assessing Evidence for Nursing Practice. Wolters Kluwer Health, Philadelphia.

[29] Kvale, S. and Brinkmann, S. (2015) Interviews: Learning the Craft of Qualitative Research Interviewing. 3rd Edition, Sage Publications, Thousand Oaks, CA.

[30] Gadamer, H.G. (2004) Truth and Method. Interactive Sciences Ltd., Gloucester.

[31] Denzin, N.K. and Lincoln, Y.S. (2008) Collecting and Interpreting Qualitative Materials. Sage, Los Angeles.

[32] Morrison-Beedy, D., Cõteé-Arsenault, D. and Fischbeck Feinstein, N. (2001) Maximizing Results with Focus Groups: Moderator and Analysis Issues. Application of Nursing Research, 14, 48-53. https://doi.org/10.1053/apnr.2001.21081

[33] World Medical Association (2004) Declaration of Helsinki. http://www.who.int/workforcealliance/members_partners/member_list/wma/en/

[34] Northern Nurses Federation (2003) Ethical Guidelines for Nursing Research in the Nordic Countries. https://dsr.dk/sites/default/files/479/ssns_etiske_retningslinjer_0.pdf

[35] Sporrong, S.K., Höglund, A.T., Hansson, M.G., Westerholm, P. and Arnetz, B. (2005) We are White Coats Whirling Round-Moral Distress in Swedish Pharmacies. Journal of Pharmacy World Science, 27, 223-229. https://doi.org/10.1007/s11096-004-3703-0 
[36] Kälvemark, S., Höglund, A.T., Hansson, M.G., et al. (2004) Living with Conflicts-Ethical Dilemmas and Moral Distress in the Health Care System. Social Science Medicine, 58, 1075-1084. https://doi.org/10.1016/S0277-9536(03)00279-X

[37] Raines, M.L. (2000) Ethical Decision Making in Nurses. Relationships among Moral Reasoning, Coping Style, and Ethics Stress. JONAS Healthcare Law Ethics Regulation, 2, 29-41. https://doi.org/10.1097/00128488-200002010-00006

[38] Lützén, K., Cronqvist. A., Magnusson, A., et al. (2003) Moral Stress: Synthesis of a Concept. Nursing Ethics, 10, 312-322. https://doi.org/10.1191/0969733003ne608oa

[39] Cronqvist, A., Theorell, T., Burns, T., et al. (2004) Caring about-Caring for: Moral Obligations and Work Responsibilities in Intensive Care Nursing. Nursing Ethics, 11, 63-76. https://doi.org/10.1191/0969733004ne667oa

[40] Zydziunaite, V. and Suominen, T. (2014) Leadership Styles of Nurse Managers in Ethical Dilemmas: Reasons and Consequences. Contemporary Nurse, 48, 150-167. https://doi.org/10.1080/10376178.2014.11081937

[41] Bowman, K. (2010) Leadership Dimensions: Trepidation: A Family Member's Response to Shift Change in the Intensive Care Unit. Dimension of Critical Care Nursing, 29, 331-337. https://doi.org/10.1097/DCC.0b013e3181f0c1b5

[42] Lindh, I.B., Severinsson, E. and Berg, A. (2007) Moral Responsibility: A Relational Way of Being. Nursing Ethics, 14, 129-140. https://doi.org/10.1177/0969733007073693

[43] Redman, B.K. (2005) The Ethics of Self-Management Preparation for Chronic llness. Nursing Ethics, 12, 361-369. https://doi.org/10.1191/0969733005ne801oa

[44] Holm, A.L. and Severinsson, E. (2013) Reflections on the Ethical Dilemmas Involved in Promoting Self-Management. Nursing Ethics, 21, 402-413. https://doi.org/10.1177/0969733013500806

[45] Hansson, M.G. (2002) Imaginative Ethics-Bringing Ethical Praxis into Sharper Relief. Medical Health Care Philosophy, 7, 360-365.

[46] Rodgers, V. and Neville, S. (2007) Personal Autonomy for Older People Living in Residential Care: An Overview. Nursing Practice, 23, 29-36.

[47] Johnstone, M. (2004) Bioethics. A Nursing Perspective. 4th Edition, Elsevier, Sydney.

[48] Beauchamp, T. and Childress, J. (2001) Principles of Biomedical Ethics. 5th Edition, Oxford University Press, New York.

[49] Butler, R.N. (2005) Ageism: Looking Back Over my Shoulder. Generations, 3, 84-86. http://www.ingentaconnect.com/content/asag/gen/2005/00000029/00000003/art000 16

[50] Botega, N.J., Silva, S.V., Reginato, D.G., Rapeli, C.B., Cais, C.F.S., Mauro, M.L.F., Stefanello, S. and Cecconi, J.P. (2007) Maintained Attitudinal Changes in Nursing Personnel after a Brief Training on Suicide Prevention. Suicide \& Life-Threatening Behavior, 37, 145-153.

https://search.proquest.com/docview/224871554?accountid=15685 https://doi.org/10.1521/suli.2007.37.2.145

[51] Sørlie, V., Kihlgren, A. and Kihlgren, M. (2005) Meeting Ehical Challenges in Acute Nursing Care as Narrated by Registered Nurses. Nursing Ethics, 12, 133-142. https://doi.org/10.1191/0969733005ne770oa

[52] Cottrell, S. (2001) Occupational Stress and Job Satisfaction in Mental Health Nursing: Focused Interventions through Evidence-Based Assessment. Journal of Psychiatric \& Mental Health Nursing, 8, 157-164. 
https://doi.org/10.1046/j.1365-2850.2001.00373.x

[53] Grace, P.J. (2001) Professional Advocacy: Widening the Scope of Accountability. Nursing Philosophy, 2, 151-162. https://doi.org/10.1046/j.1466-769X.2001.00048.x

[54] Glasberg, A.L. (2007) Stress of Conscience and Burnout in Healthcare: The Danger of Deadening One's Conscience. Umeå University, Medical Dissertations, Umeå.

[55] Lützen, K., Dahlqvist, V., Eriksson, S. and Norberg, A. (2006) Developing the Concept of Moral Sensitivity in Health Care Practice. Nursing Ethics, 13, 187-196. https://doi.org/10.1191/0969733006ne837oa

[56] Redman, B.K. (2007) Responsibility for Control; Ethics of Patient Preparation for Self-Management of Chronic Disease. Bioethics, 21, 243-250. https://doi.org/10.1111/j.1467-8519.2007.00550.x

[57] Holm, A.L. and Severinsson, E. (2015) Mapping Psychosocial Risk and Protective Factors in Suicidal Older Persons-A Systematic Review. Open Journal of Nursing, 5, 260-275. https://doi.org/10.1111/j.1467-8519.2007.00550.x

[58] Nordenfelt, L. (2004) The Varieties of Dignity. Health Care Analyses, 12, 69-81. https://doi.org/10.1023/B:HCAN.0000041183.78435.4b

[59] Martin, R., Williams, C. and O’Neill, D. (2009) Retrospective Analysis of Attitudes to Ageing in the Economist: Apocalyptic Demography for Opinion Formers. BMJ, 339, b4914. https://doi.org/10.1136/bmj.b4914

[60] McDonough, P. and Polzer, J. (2012) Habitus, Hysteresis and Organizational Change in the Public Sector. Canadian Journal of Sociology, 37, 357-379.

[61] Eriksson, K. (2006) The Suffering Human Being. Nordic Studies Press, Chicago.

[62] Vesterinen, S., Suhonen, M., Isola, A., Paasivaara, L. and Laukkala, H. (2013) Nurse Managers' Perceptions Related to their Leadership Styles, Knowledge and Skills in these Areas-A Viewpoint: Case of Health Centre Wards in Finland. ISRN Nursing, 2013, 1-13. https://doi.org/10.1155/2013/951456

[63] Rosengren, K., Athlin, E. and Segesten, K. (2007) Presence and Availability: Staff Conceptions of Nursing Leadership on an Intensive Care Unit. Journal of Nursing Management, 15, 522-529. https://doi.org/10.1111/j.1365-2834.2007.00712.x

[64] Holm, A.L., Berland, A.K. and Severinsson, E. (2016) Older Patients' Involvement in Shared Decision-Making-A Systematic Review. Open Journal of Nursing, 6, 170-185. http://file.scirp.org/pdf/OJN_2016031414045711.pdf

[65] Shearer, D.A. (2012) Management Styles and Motivation. Radiology Management, 34, 47-52. 